\title{
Nanotechnology for Delivery of Drugs to the Brain for Epilepsy
}

\author{
Margaret F. Bennewitz and W. Mark Saltzman \\ Department of Biomedical Engineering, Yale University, New Haven, Connecticut 06520
}

\begin{abstract}
Summary: Epilepsy results from aberrant electrical activity that can affect either a focal area or the entire brain. In treating epilepsy with drugs, the aim is to decrease seizure frequency and severity while minimizing toxicity to the brain and other tissues. Antiepileptic drugs (AEDs) are usually administered by oral and intravenous routes, but these drug treatments are not always effective. Drug access to the brain is severely limited by a number of biological factors, particularly the blood-brain bar-
\end{abstract}

rier, which impedes the ability of AEDs to enter and remain in the brain. To improve the efficacy of AEDs, new drug delivery strategies are being developed; these methods fall into the three main categories: drug modification, blood-brain barrier modification, and direct drug delivery. Recently, all three methods have been improved through the use of drug-loaded nanoparticles. Key Words: Epilepsy, seizures, antiepileptic drugs, blood-brain barrier, CNS delivery, drug delivery systems.

\section{INTRODUCTION}

Epilepsy is characterized by abnormal electrical activity within the brain, which can result in either generalized or partial seizures. Generalized seizures are widespread, affecting both hemispheres of the brain. In contrast, partial seizures originate at a focus and are isolated to specific areas of the brain. The presence of a focal lesion can sometimes be detected by electroencephalographic readings and functional magnetic resonance imaging, ${ }^{1}$ allowing for the possibility of targeted treatment to the affected area. In either generalized or partial seizures, the goal is to deliver antiepileptic drugs (AEDs) to the brain in quantities sufficient to reduce the frequency and severity of seizures without causing adverse effects.

The current approach to drug therapy of seizures involves producing high levels of AEDs in the blood, through the use of pills or of intravenous injections. In either case, drug must enter the brain by crossing from the blood into the brain tissue. This transvascular route seems reasonable, given the high vascularity of the brain. Comprised of 100 billion capillaries, separated by only $40 \mu \mathrm{m},{ }^{2}$ the intricate network of intracranial vessels has the potential to distribute drugs throughout the whole brain.

Nonetheless, these methods are severely limited by obstacles that prevent AEDs from reaching the brain at therapeutic concentrations that can be maintained over time. The biggest obstacle is the blood-brain barrier (BBB). Structural characteristics of the brain capillaries contribute to tight regulation of molecular transport from the blood into the brain interstitial fluid (FIG. 1): the absence of fenestrae in endothelial cells, the presence of tight junctions between endothelial cells, a decreased number of pinocytotic vesicles, ${ }^{3}$ and the direct communication between endothelial cells and astrocytes. ${ }^{4}$ As a result, only low molecular weight $(<1000 \mathrm{Da})$ lipidsoluble molecules can freely cross the BBB. In addition, molecular efflux pumps, which use cellular energy to pump drugs that might cross the BBB back into the vessel lumen, decrease the ability of many prospective AEDs to accumulate in the brain. Even before drugs can reach the brain, factors such as systemic toxicity ${ }^{5}$ and macrophage phagocytosis within the reticuloendothelial system $^{6}$ limit the success of the transvascular route.

Several new approaches are being developed in an attempt to increase the entry and persistence of AEDs in the brain. The main strategies are drug delivery systems, prodrugs, efflux pump inhibition, hyperosmolar BBB opening, and the circumvention of the BBB through direct drug delivery to the ventricles and cortex. In addition, gene and cell therapies ${ }^{5}$ for the treatment of epilepsy are also currently being developed, although these are outside the scope of this review.

\section{DRUG MODIFICATION}

Address correspondence and reprint requests to: Prof. W. Mark Saltzman, Department of Biomedical Engineering, Yale University, 414 Malone Engineering Center, 55 Prospect Street, New Haven CT 06520-8260. E-mail: mark.saltzman@yale.edu.
An alternative to delivering free AEDs to the brain is to encapsulate the drugs within a nanoscale delivery 


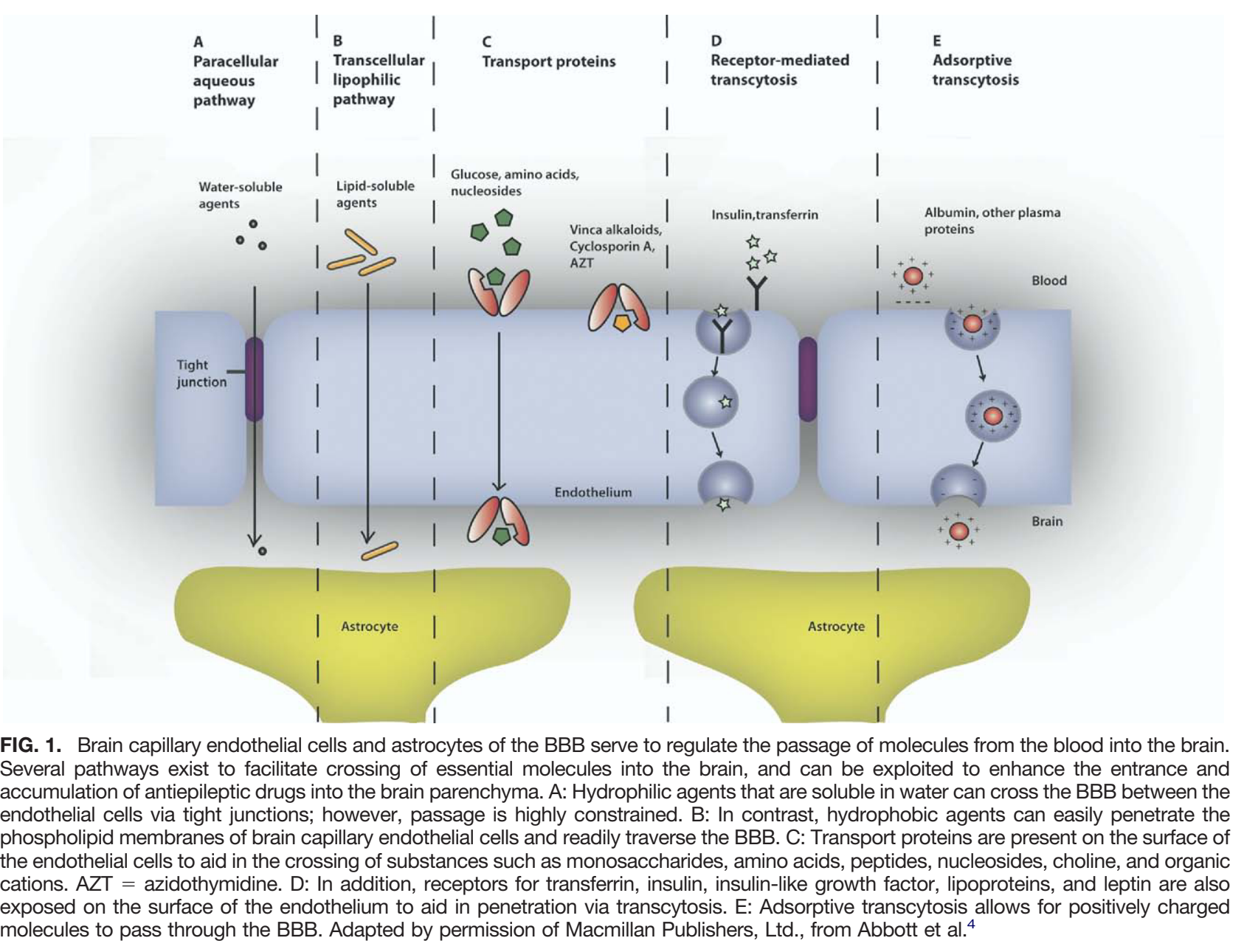

system (FIG. 2). Polymer nanoparticles (NPs) and liposomes are the most popular, but several other means of delivery have also been studied including dendrimers, micelles, carbon nanotubes, emulsions, solid lipid NPs, and nanostructured lipid carriers. ${ }^{7-10}$ (Liposomes are indeed nano-sized particles, but in this review we use NP to refer to particles made of solid polymers with dispersed or encapsulated drug.) Compared with liposomes, NPs possess superior stability when placed in both biological fluids and under storage conditions, and are easier to prepare. ${ }^{11,12}$ Another advantage of NPs is their potential to produce sustained and controlled release of the drug over time; liposomes generally do not have this potential, although a few studies claim that it is possible to tailor liposomes to release drugs in a sustained fashion. ${ }^{13,14}$ Both NPs and liposomes protect drugs from in vivo degradation, while reducing toxicity. ${ }^{15,16}$

\section{Nanoparticles}

Nanoparticles can be as small as $10 \mathrm{~nm}$ and as large as $1000 \mathrm{~nm}$, and are typically composed of biodegradable polymers such as poly(alkylcyanoacrylates), polyesters such as poly(lactic acid), poly(glycolic acid), $\operatorname{poly}(\varepsilon-$ caprolactone) and their copolymers, poly(methylidene malonate), and polysaccharides. ${ }^{12}$ Poly(lactic-co-glycolic acid) (PLGA) is one of the most common polymers used in making NPs, because of its safety, biocompatibility, and long use in delivery systems and devices approved by the U.S. Food and Drug Administration. The degradation properties of PLGA can be tailored to desired applications, by changing the ratio of the copolymers.

The method for NP synthesis depends on the size, solubility, and the type of drug to be encapsulated (FIG. 3). For delivery to the brain, there is probably an optimal size for NPs: small enough to travel through the physical restrictions presented by the brain interstitial space $(\sim 50$ $\mathrm{nm}^{17}$ ), but large enough to allow for sufficient drug loading. Size can be tailored by altering the NP-making process. ${ }^{18,19}$ The surface charge of the NP can be an important feature in its effectiveness, because neutral or negatively charged surfaces experience a greater volume of distribution when directly delivered in the brain $^{20}$; surface charge can be modified in the fabrication process in a variety of ways. In addition, the NP-making process can be altered to encapsulate both hydrophobic and hydrophilic drugs (FIG. 3). ${ }^{21}$ Once the drugs are loaded into the NPs, they are released through a combi- 


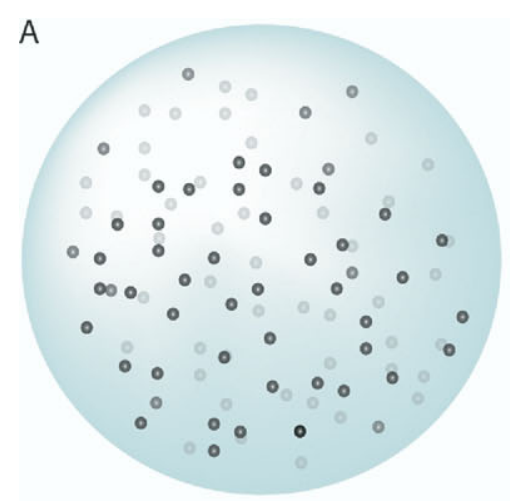

Polymeric NPS

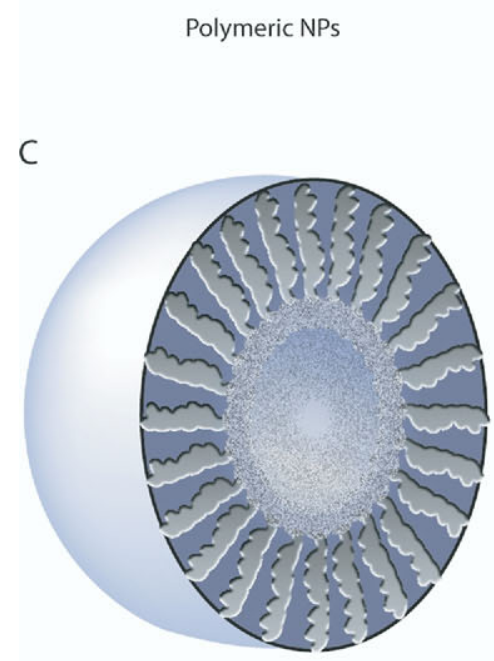

Polymeric Micelles

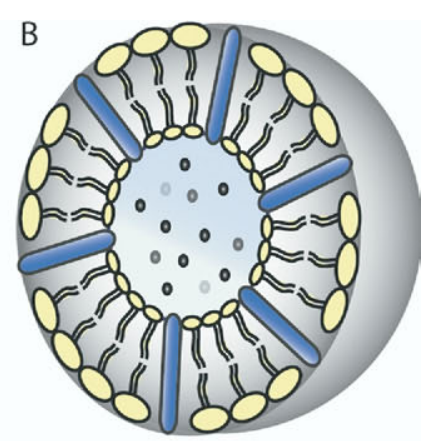

Liposomes

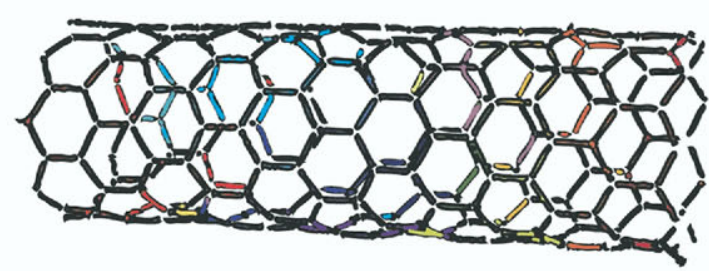

Carbon Nanotubes

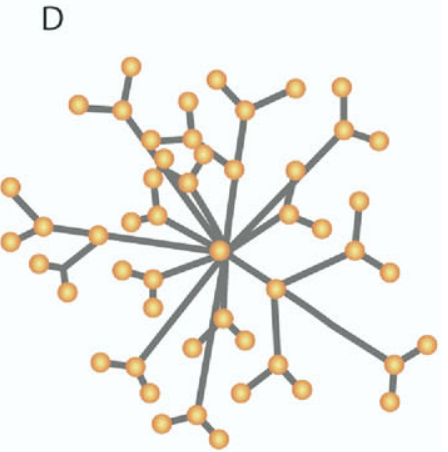

Dendrimers

FIG. 2. Major classes of nanocolloidal carriers used in drug delivery. A: Polymeric nanoparticles (NPs) are typically made of biodegradable polymers, and entrap drugs via encapsulation or polymer-drug conjugation. B: Liposomes are made up of phospholipids and contain an aqueous core surrounded by a lipid bilayer. Hydrophilic drugs can be incorporated into the core; hydrophobic and amphiphilic drugs can be integrated into the bilayer. C: Polymeric micelles are formed in an aqueous environment from the associations of block copolymers containing both hydrophilic and hydrophobic segments. The hydrophobic core can be loaded with lipophilic drugs, and the hydrophilic surface serves to increase the stability of the micelles in water. D: Dendrimers contain many polymeric monomers that form branched, tree-like structures, allowing drugs to be attached to its many arms. E: Carbon nanotubes, made of benzene rings, can carry drugs inside the lumen of the tube or attached to the sides.

nation of desorption, diffusion, and polymer degradation or erosion. ${ }^{22}$ In vivo, variables such as the molecular weight of the polymer and mechanism of erosion (bulk or surface) affect the speed of drug release, which can vary from a few hours or days to many months. ${ }^{23}$

\section{Liposomes}

Liposomes are self-assembled structures with properties similar to biological plasma membrane: an aqueous core is surrounded by single or multiple bilayers of phospholipids (FIG. 4). Liposomes range in diameter from approximately $50 \mathrm{~nm}$ to $1 \mu \mathrm{m} .{ }^{11}$ The unique arrangement of aqueous and lipid components allows for the encapsulation of hydrophilic, hydrophobic, and amphiphilic drugs within liposomes (FIG. 5A) ${ }^{12}$ Liposomes deliver drugs to cells by liposome entry into the cell or by release of drug into the extracellular space, with subsequent diffusion of drug through the cell plasma membrane. To provide the opportunity for stimulus-dependent release of drugs from liposomes, temperature-sensitive and $\mathrm{pH}$-sensitive liposomes have been developed. Temperature-sensitive liposomes release the encapsulated drug in response to an increase in temperature (to $41^{\circ} \mathrm{C}-42^{\circ} \mathrm{C}$ ) applied at the target site, ${ }^{24}$ whereas $\mathrm{pH}$-sensitive liposomes discharge their drug contents in response to an acidic environment. ${ }^{25}$ As with NPs, liposomes delivered to the brain can be designed to meet specific requirements of $\operatorname{size}^{17}$ and charge $e^{20}$ to provide optimal volume of distribution.

\section{Stealth polymers}

Encapsulating drugs into either liposomes or NPs protects the drugs from in vivo degradation and reduces toxicity; however, once delivered by intravenous injection, ordinary NPs and liposomes are cleared from the plasma within a few minutes ${ }^{26}$ due to opsonization and subsequent phagocytosis by the cells of the reticuloendothelial system. ${ }^{11}$ To increase circulation time, polymers such as poly(ethylene glycol) (PEG), polysaccharides, poly- 


\section{Single Emulsion (O/W)}

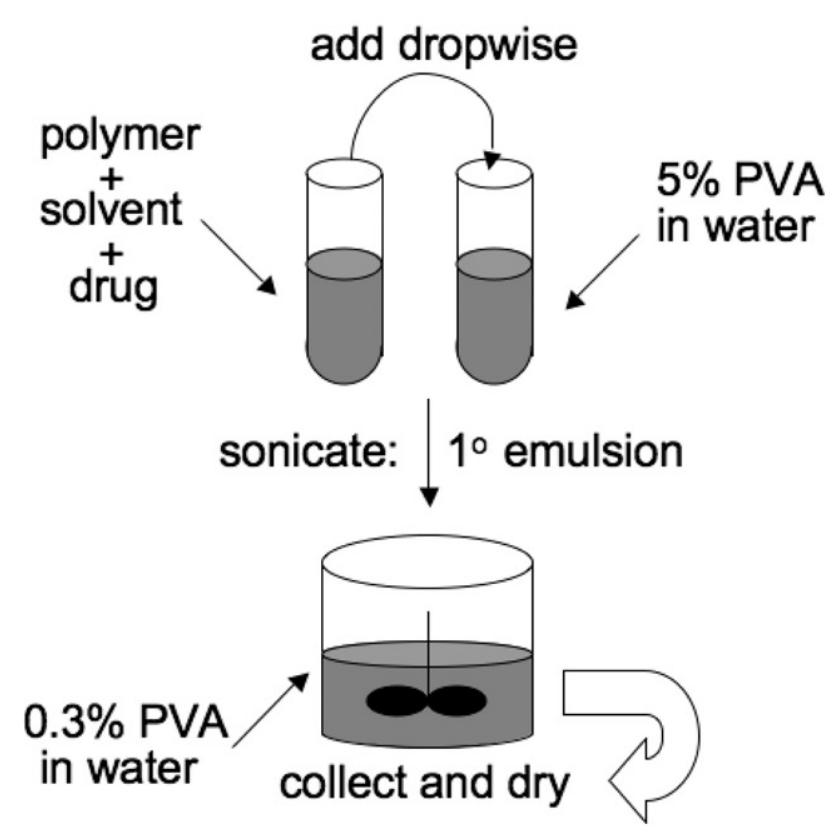

\section{Double Emulsion (W/O/W) add dropwise}

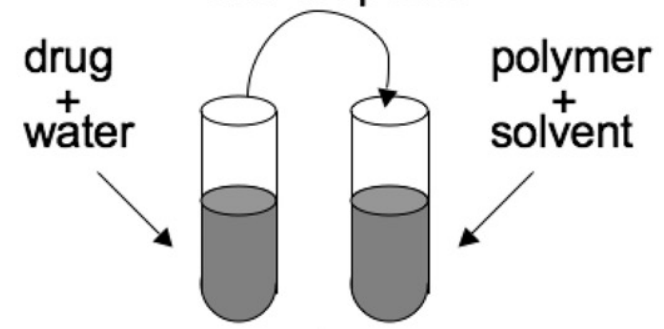

sonicate: $\downarrow 10$ emulsion add dropwise

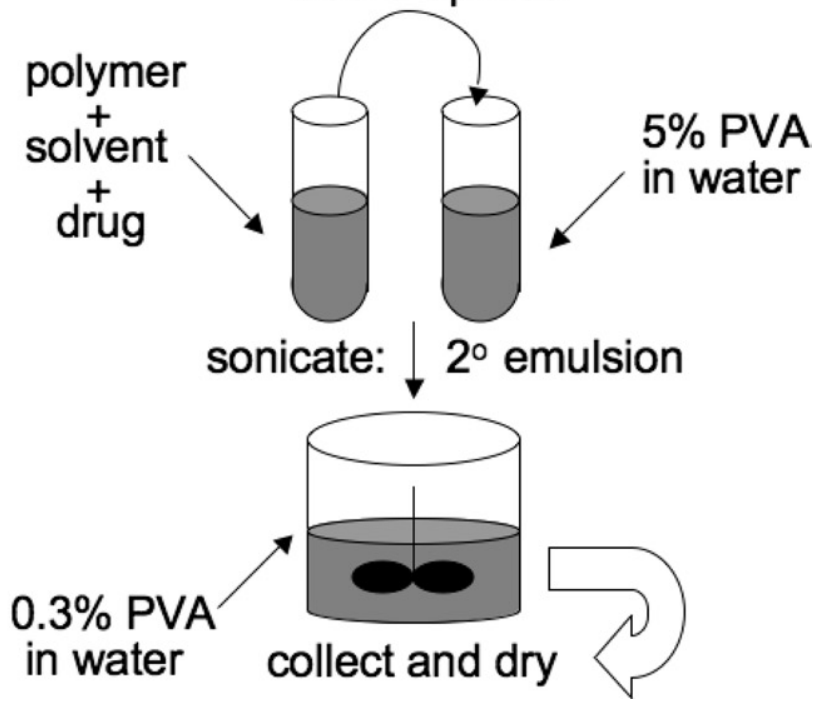

FIG. 3. Single and double emulsion processes for nanoparticle fabrication. Single emulsion (oil-in-water, O/W) is commonly used to encapsulate hydrophobic drugs, because the drug and polymer are dissolved in an organic solvent such as methylene chloride. On the contrary, double emulsion (water-in-oil-in-water, W/O/W) is typically used to encapsulate hydrophilic drugs, because the drug is suspended in water. In addition, single emulsion requires one sonication step, but double emulsion requires two. PVA, poly(vinyl alcohol).

(acrylamide), and poly(vinyl alcohol) have been conjugated to the surfaces of NPs and liposomes. The addition of these tethered polymer chains produces what is termed a stealth character; that is, the particles are no longer opsonized or recognized by the reticuloendothelial system and therefore circulate for longer periods.

Poly(ethylene glycol) is the most commonly used polymer for producing stealth particles. ${ }^{27}$ It is a hydrophilic polymer that resists the binding of plasma proteins (FIG. 5B), thus preventing opsonization and recognition by phagocytes. ${ }^{11}$ In vivo, coating the surfaces of NPs and liposomes with PEG increases circulation times from several minutes to many hours ${ }^{27-31}$; an example is shown in Figure 6. The effectiveness of PEG depends on chain length and surface density, with the latter being more important. From mathematical estimations based on the principles of free energy, it appears that longer and more densely packed PEG chains create the most favorable conditions for preventing plasma protein binding. ${ }^{32}$ The
PEG can be incorporated onto the surface of colloidal carriers through covalent attachment, physical entrapment, adsorption, or as a copolymer. ${ }^{33}$

Even though the incorporation of PEG has been shown to increase circulation time, there is no guarantee that PEG-modified NPs and liposomes delivered through intravenous injection will cross the BBB. Targeting moieties must also be added to the nano-delivery systems, in addition to PEG, to facilitate penetration of the BBB.

\section{Targeting}

Ligand-specific transport systems are essential for delivery of nutrients across the BBB. Brain capillaries contain carrier-mediated transport systems for monosaccharides, amino acids, peptides, choline, and organic cations, and receptor-mediated transcytosis systems for substances such as lipoproteins, transferrin (Tf), insulin, insulin-like growth factor, and leptin (FIG. 1). ${ }^{34}$ Because these physiological transport systems move large numbers 
<smiles>[R]OP(=O)([O-])OCC(COC([R])=O)OC([R])=O</smiles>

Formula for $\mathrm{R}_{3}$

- $\mathrm{CH}_{2} \mathrm{CH}_{2} \mathrm{NH}_{3}{ }^{+}$

- $\mathrm{CH}_{2} \mathrm{CH}_{2} \mathrm{~N}\left(\mathrm{CH}_{3}\right)_{3}^{+}$

- $\mathrm{CH}_{2} \mathrm{CH}(\mathrm{OH}) \mathrm{CH}_{2} \mathrm{OH}$

- $\mathrm{CH}_{2} \mathrm{CH}\left(\mathrm{NH}_{3}{ }^{+}\right) \mathrm{COO}-$

OH

$\mathrm{HOH} \mathrm{H} \mathrm{H}$

$\mathrm{H} \mathrm{OH}$

\section{Phospholipid Name}

Phosphatidylethanolamine

Phosphatidylcholine

Phosphatidylglycerol

Phosphatidylserine

Phosphatidylinositol

\section{$\mathrm{R}_{1}, \mathrm{R}_{2}=$ hydrocarbon chains of fatty acids}

$$
\mathrm{R}_{3}=\text { head group }
$$

FIG. 4. Structures of common phospholipids used in making liposomes. Each type of phospholipid contains a hydrophilic head group $\left(R_{3}\right)$ and two hydrophobic tails $\left(R_{1}, R_{2}\right)$. In aqueous solution, the hydrophobic tails will segregate together to form a bilayer structure, with the hydrophilic head groups facing outward into the solution on the outside and into the aqueous core on the inside.

of molecules into the brain every minute, they are attractive targets for drug design. These carrier systems can be used to transport small drugs and proteins, such as L-dopa for treating Parkinson's disease, and antibodies.

One idea for increasing the uptake of particulate delivery systems into the brain involves targeting by in- corporation of ligands corresponding to these carriers or endocytosis systems, which will facilitate transport across the BBB. ${ }^{35}$ Targeting ligands can be added directly or indirectly to the colloidal carriers. Targeting is most effective when the ligands are conjugated to the ends of the PEG chains (or other spacer molecules);
A

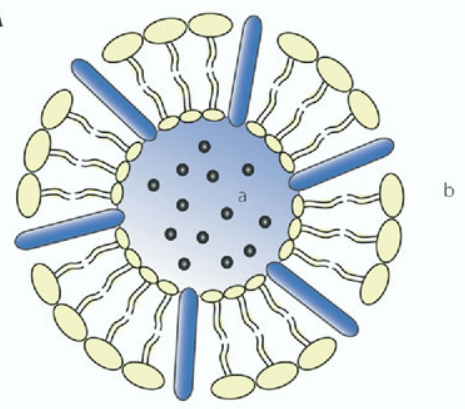

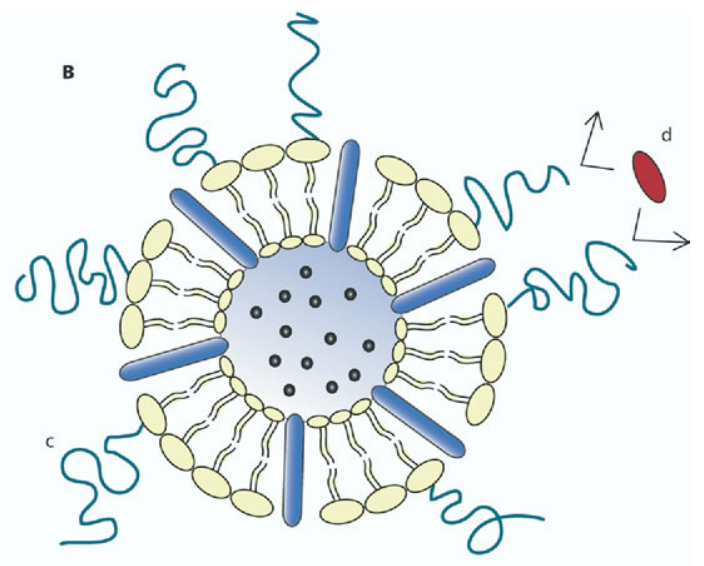

c

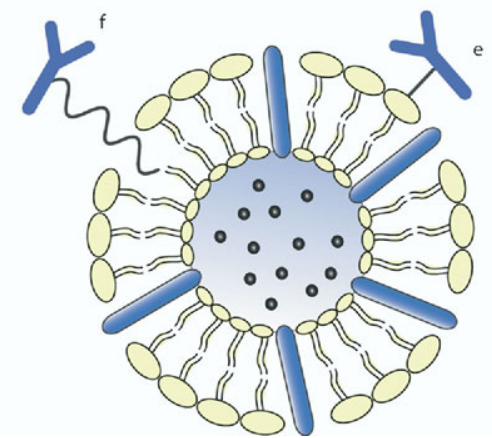

FIG. 5. Liposome structure and alterations for enhanced circulation and BBB penetration. A: Hydrophilic drugs (a) can be entrapped within the aqueous core of the liposome, and hydrophobic or amphiphilic drugs (b) can be incorporated into the lipid bilayer. B: Stealth polymers, such as poly(ethylene glycol) (PEG) (c), can be conjugated to the liposome surface to resist protein adsorption (d) and result in an increased plasma circulation time. C: To aid in targeting the liposome to and across the BBB, ligands can be attached directly to the surface (e) or to the end of the PEG chains (f). The latter conformation is ideal, because direct surface conjugation can cause the ligand to experience steric hindrance from the PEG chains in their uncoiled state. 


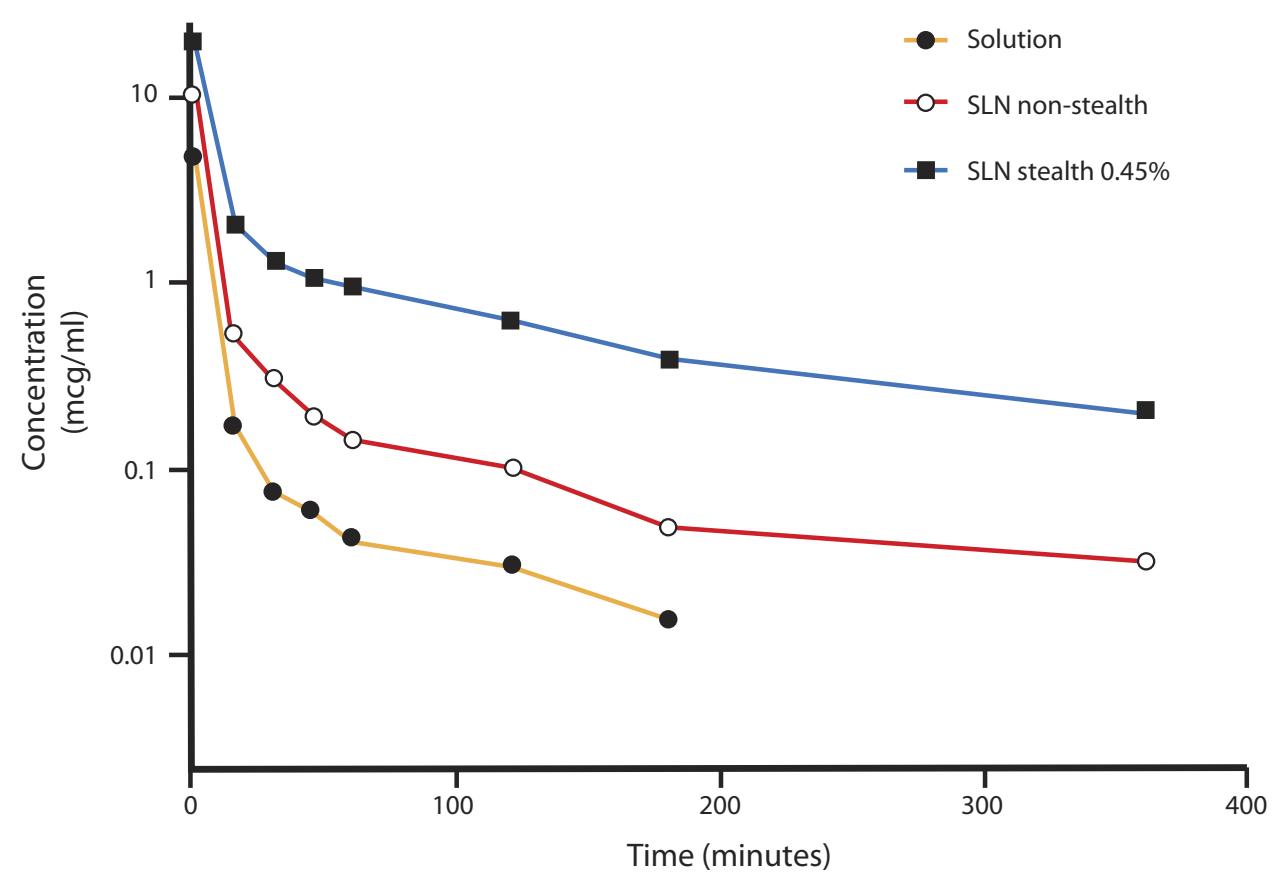

FIG. 6. Incorporation of PEG onto the surface of nanoparticles significantly increases in vivo circulation time. This example shows the plasma concentration of an anticancer drug, doxorubicin, over time after intravenous administration of solid lipid nanoparticles (SLN) containing various amounts of stealth polymer. As the concentration of stealth polymer was increased, greater plasma levels of doxorubicin were achieved. Adapted from Zara et al. ${ }^{115}$

addition of ligands to the surface of the carrier can be hindered by steric effects, precluding target-ligand contact and recognition (FIG. 5C). ${ }^{36}$ One limitation of this technique is that these systems mimic natural substrates, so competition with natural compounds is likely to occur.

To take advantage of carrier-mediated transport systems, natural substances, such as mannose and choline, have been attached to the surface of colloidal carriers. The incorporation of mannose derivatives onto liposomes has yielded mixed results. Whereas one investigation found that the targeted liposomes were able to cross the BBB via the glucose transporter and appear in the mouse brain, ${ }^{37}$ another study did not find that brain uptake for targeted liposomes was increased, compared with control liposomes, in the rat brain. ${ }^{38}$

Researchers have used a variety of approaches to examine enhanced transport of particles across the BBB. The transport of charged NPs coated with dipalmitoyl phosphatidyl choline and cholesterol were investigated in an in vitro model of the BBB containing both bovine brain capillary endothelial cells and rat astrocytes. ${ }^{39}$ Nanoparticles coated with choline exhibited an enhanced penetration of the $\mathrm{BBB}$, three to four times greater than uncoated NPs. It is likely in this in vitro model that the NPs were able to cross by the choline transporter on the brain capillary endothelial cells, ${ }^{40}$ although it is not clear how well this model reflects in vivo BBB behavior.

In another study, MRZ 2/576, a noncompetitive NMDA receptor antagonist, was incorporated into NPs composed of poly(butylcyanoacrylate) with polysorbate 80 coated on the surface. ${ }^{41}$ When administered through intravenous injection, the anticonvulsant activity of free MRZ 2/576 lasted for only 5 to $15 \mathrm{~min}$; however, entrapment of MRZ 2/576 into the NPs served to increase its antiepileptic effects up to $210 \mathrm{~min}$. In this case, it is speculated that the polysorbate 80 coating on the NPs binds to apolipoproteins $\mathrm{B}$ and $\mathrm{E}$ when it comes in contact with blood. ${ }^{42}$ This newly formed lipoprotein coat, which is made up of natural lipoproteins, might mediate transport across the BBB via the low-density lipoprotein receptors on brain capillary endothelial cells. ${ }^{42}$ Some issues to resolve in using this method include the desorption of the polysorbate 80 coating from the NPs, limited time of therapeutic effectiveness due to rapid NP degradation, and the associated toxicity that can result from either the polymer or the high concentrations of surfactant. ${ }^{43}$

The receptor-mediated transport of Tf can also be exploited to increase the penetration of nanosystems across the BBB. Nanoparticles made of chitosan, a natural polymer, were produced using avidin-biotin conjugation to attach the monoclonal antibody, OX26, to the end of PEG chains that were incorporated on the particle surface. ${ }^{44}$ The OX26 antibody promotes BBB penetration through the $\mathrm{Tf}$ receptor (TfR) and has been found to be more successful than using Tf itself. (The normal amount of $\mathrm{Tf}$ in the plasma is sufficient to nearly saturate its receptors; therefore, any carrier coated with $\mathrm{Tf}$ would have a difficult time crossing the BBB via the TfR due to competition with the physiological levels of Tf. OX26 exhibits increased efficacy over $\mathrm{Tf}$ because it binds to an extracellular domain on the TfR 
that differs from the Tf binding domain.) When fluorescently labeled NPs with and without OX26 were administered through intravenous injection in mice, fluorescence appeared in the brain only with antibody-targeted NPs, indicating the facilitation of BBB crossing with the addition of OX26. ${ }^{44}$ Other studies with immunoliposomes and OX26 have also found promising results. ${ }^{45-48}$

As an alternative to targeted nano-carriers, free drug can be delivered across the BBB by having a structure similar to the endogenous substances that are transported into the brain. A prime example is the AED gabapentin, whose $\gamma$-amino acid structure mimics the laevo form of naturally occurring large neutral $\alpha$-amino acids. The structural likeness between gabapentin and the L-type amino acids suggests that gabapentin is able to cross the $\mathrm{BBB}$ by the L-type amino acid transporter system. ${ }^{49}$ However, in using this technique, problems associated with free drugs still remain, including systemic toxicity and in vivo degradation.

\section{Prodrugs}

Prodrugs are made of a drug attached to a distinct compound that is removable via enzymatic cleavage or hydrolysis in vivo. The prodrug is inactive; an active drug is formed by liberation from the prodrug, with the release of an additional compound or moiety. The attached moiety can serve to make the prodrug more lipophilic, therefore increasing its tendency to cross the BBB. A prodrug of valproic acid (VPA), DP-VPA (DP16), was developed by this strategy. DP-VPA is synthesized by linking VPA with lecithin, a phospholipid, which ensures the inactivation of the parent drug in the systemic circulation. ${ }^{50}$ Once DP-VPA reaches the seizure focus, active VPA is released following cleavage of lecithin by $\mathrm{A}_{2}$ phospholipases, which are overactive at the target site. Unnecessary activation of the prodrug is prevented when the seizure stops, because enzymatic activity decreases as the neurons exit their excited states. ${ }^{51}$ By limiting the activation of the prodrug to the seizure focus, systemic toxicity is greatly reduced. In several animal models of epilepsy, DP-VPA is more effective at preventing seizures than is VPA; however, the prodrug does not have an anticonvulsive effect in all seizure models. ${ }^{51}$

Another prodrug, fosphenytoin, is made of the parent drug phenytoin and an attached phosphate ester. ${ }^{52}$ The phosphate ester renders the prodrug inactive, and increases the water solubility of phenytoin. When infused into muscle or directly into the bloodstream, fosphenytoin is cleaved by naturally occurring alkaline phosphatases to yield active phenytoin. In addition to phenytoin, its metabolism yields phosphate and formaldehyde; however, the amounts produced are low, and no toxicity has been described to date. ${ }^{52,53}$ Compared with phenytoin, fosphenytoin can be administered more rapidly through intravenous infusion and is associated with a reduction in discomfort at the delivery site. ${ }^{54}$ In a clinical study involving 81 patients with status epilepticus, fosphenytoin exhibited anticonvulsant effects in 76 of the patients. ${ }^{54}$

XP13512 is an isobutanoyloxyethoxy carbamate prodrug of gabapentin. ${ }^{52}$ In vivo, XP13512 is transported by the monocarboxylate transporter type 1 and the sodiumdependent multivitamin transporter, both of which are expressed throughout the intestine. The prodrug is cleaved by endogenous esterases that release the active gabapentin; rapid metabolism of the prodrug was observed in tissue preparations of the intestine and liver in various species, including humans. ${ }^{55}$ Following oral ingestion in monkeys, the bioavailability of XP13512 was greatly enhanced over the parent drug ( $84 \%$ vs $25 \%$, respectively). ${ }^{56}$

\section{BBB MODIFICATION}

\section{Efflux pumps}

An alternative approach to enhancing transport across the BBB is to couple drug delivery to manipulations that transiently modify the permeability of the barrier. P-glycoprotein (Pgp), multidrug resistance-associated proteins (MRP), and the breast cancer resistance protein (BCRP) are members of the ATP-binding cassette (ABC) superfamily. ABC transporters, expressed on the apical membrane of brain capillary endothelial cells, hydrolyze ATP to move molecules against their concentration gradients into the systemic circulation; these transporters have the potential to affect the fate of drug localization within the CNS. ${ }^{57}$

In patients with intractable epilepsy, Pgp, several of the MRPs, and BCRP are overexpressed in epileptogenic brain tissue, within brain capillary endothelial cells, astrocytes, and neurons. ${ }^{58-67}$ Pgp is translated from $A B C B 1$, a member of the ATP binding cassette gene family (previously MDRI), and Pgp expression is augmented in drug-resistant epileptic patients. ${ }^{58}$ The inability of some epileptic patients to benefit from AED treatment may be due to the effective pumping of these drugs out of the brain into the systemic circulation, which prevents therapeutic concentrations from being achieved in the brain.

Blocking $\mathrm{ABC}$ transporters in the brain has been investigated as a possible means of increasing the success of anticonvulsant treatment in these patients. The pumping action of Pgp is inhibited by verapamil, a calciumchannel blocker. As an example of this approach, verapamil and AEDs were administered to a young woman with drug-resistant epilepsy; the patient acquired a greater control over her seizures, and so experienced an enriched enjoyment of daily life. ${ }^{68}$ In another study, ${ }^{69}$ verapamil and a variety of AEDs were given via intravenous infusion to an 11-year-old boy with status epilepticus; the patient was unconscious and resistant to the usual AED treatment. One and a half hours after vera- 
pamil administration began, the seizure state ceased and the boy became conscious. The favorable outcomes experienced by these two patients may not be solely due to the inhibition of $\mathrm{Pgp}^{70}$; verapamil is a nonspecific, firstgeneration inhibitor of Pgp and can also affect calcium channels and prevent the conversion of AEDs to metabolites. ${ }^{71}$ More specific inhibitors may be needed.

Probenecid, an inhibitor of MRP1/MRP2, was tested for its effects on the ability of phenytoin to accumulate in the rat brain. ${ }^{59}$ At 30 min before intraperitoneal administration of phenytoin, probenecid was delivered intracranially through a microdialysis probe into the motor cortex. Treatment with probenecid significantly improved the concentration of phenytoin in the brain extracellular fluid. Other investigations supported these observations by comparing the brain:blood phenytoin ratio with and without the addition of probenecid ${ }^{72}$; rats receiving the MRP inhibitor experienced higher levels of phenytoin in the brain.

Despite the positive findings achieved through the inhibition of efflux pumps, a difficulty remains, in that it is not clear that most AEDs are substrates for Pgp, MRPs, and BCRP. ${ }^{73}$ None of the traditional AEDs appear to be substrates for BCRP, suggesting that the unresponsiveness of some epileptic patients to drug treatment is not due to an increase in the presence of this transporter at the $\mathrm{BBB}^{74}$ Interpretation of results is further complicated by the discovery that the ability of efflux pumps to effectively transport substrates can vary between species. ${ }^{73}$ Thus, more research must be conducted to further understand the activity of efflux pumps on AEDs.

\section{Hyperosmolar BBB opening}

Another approach to altering the functionality of the BBB is to increase the osmolarity of the blood flowing through brain capillaries. One way to accomplish this is to inject a hyperosmolar solution of $25 \%$ mannitol intraarterially. ${ }^{75}$ The osmolarity due to mannitol reduces the size of brain capillary endothelial cells and induces widening of the tight junctions between them, thus increasing the permeability of the BBB to substances, including drugs. The advantage of this technique is that its effects are short lasting and spontaneously reversible; after mannitol administration, the BBB permeability is greatly enhanced for approximately $40 \mathrm{~min}$, but permeability returns to normal within approximately $8 \mathrm{~h} .{ }^{76}$ Ideally, the time that the BBB is open should be long enough to get the drug from the systemic circulation into the brain in therapeutic quantities, but short enough to limit both edema and toxicity, which are possible adverse effects of this procedure.

Since the first clinical trial in 1979, hyperosmolar BBB opening has been used to improve the delivery of anticancer drugs across the BBB to brain tumors. ${ }^{75,77,78}$ Despite favorable results obtained in some patients with brain tumors, it does not seem feasible to extend this type of treatment to epileptic patients. Seizures occur $7 \%$ of the time during hyperosmotic BBB opening in cancer patients who were previously seizure-free. ${ }^{75}$ Some studies report an even higher incidence: seizures began directly following opening of the BBB in $25 \%$ of the procedures delivering mannitol in combination with chemotherapy, whereas chemotherapy alone was not associated with any observations of seizures. ${ }^{79}$ In a recent study using chronic epileptic rats, disruption of the BBB with mannitol once a day for 3 days significantly intensified seizure incidence, compared with the number of seizures observed prior to treatment. ${ }^{80}$ Although none of these studies have directly investigated the delivery of AEDs to the brain in combination with hyperosmolar BBB opening, the fact that the procedure itself can generate seizures does not make it a promising mode of treatment for these patients.

\section{DIRECT DRUG DELIVERY}

\section{Intracerebroventricular administration}

As an alternative to modifying drugs or the BBB, drugs can be directly delivered behind the BBB. In intracerebroventricular administration, drug is introduced directly into the CSF, often through an outlet catheter leading from an implantable reservoir (such as the Ommaya reservoir) or a pump. Compared with the reservoir, the pump approach is more favorable, because it can achieve a continuous, elevated concentration of drug in the CSF. ${ }^{81}$ By administering the drug directly into the CSF, problems associated with intravenous delivery, such as systemic toxicity, metabolism of the drug in serum, and opsonization by serum proteins, can be diminished; however, this mode of delivery also has problems. Despite the improvement in drug concentration and half-life in the CSF, drug penetration into the brain parenchyma is restricted, with more localization at the ependymal cells lining the ventricles (FIG. 7). Although intracerebroventricular administration may be quite useful in applications that require the local deposition of drug at the ependymal surface of the brain, ${ }^{82}$ it is less useful for delivery to cells far from the ependymal surface.

Drug molecules move from CSF to brain parenchyma by diffusion, which is a slow process. To enter the parenchyma, drugs in the CSF first must navigate through barriers composed of ependymal cells and astrocytes. ${ }^{83}$ Movement in the parenchyma is also by diffusion: the high tortuosity and restricted pore size of the extracellular space greatly slows movement of drug. ${ }^{84}$ In addition, it takes only 4 to $5 \mathrm{~h}$ for CSF to be cycled through the ventricular system, upon which it exits the brain by bulk flow into the systemic circulation. ${ }^{85}$ Various studies have noted the presence of drug in the plasma after intracerebroventricular bolus injection, suggesting that some drug will exit the CSF before it can accumulate in brain tissue. ${ }^{86-88}$ Loss of drug into the blood has the potential to 


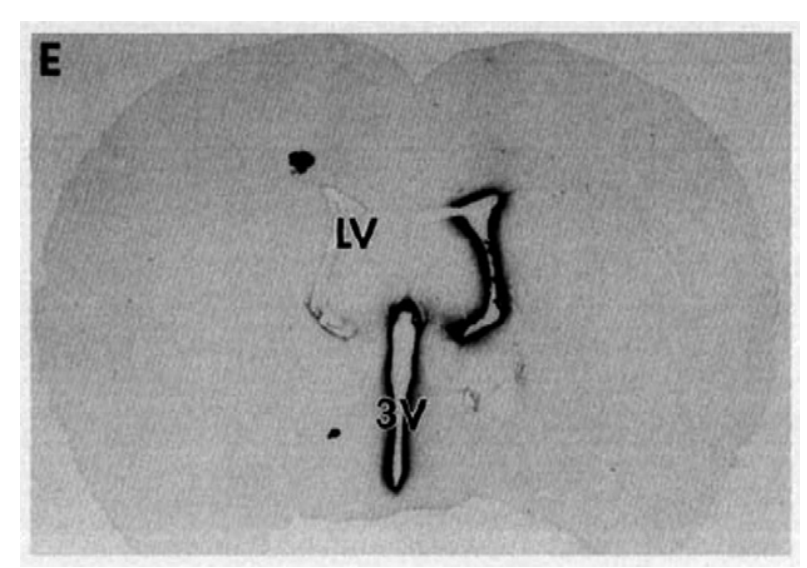

FIG. 7. Ependymal localization of radiolabeled brain-derived neurotrophic factor $\left(\left[{ }^{125} \mathrm{l}\right]\right.$-BDNF) after intracerebroventricular administration into the right lateral ventricle (LV). At $20 \mathrm{~h}$ after injection, $\left[{ }^{125} \mathrm{l}\right]-\mathrm{BDNF}$ exhibited minimal penetration into the brain parenchyma, and was concentrated along the ependymal surface along the right LV and the third ventricle (3V). Reprinted with permission from Academic Press (Yan et al. ${ }^{116}$ ).

decrease both the efficiency of delivery and the therapeutic effects, because the BBB has to be crossed for drugs to reenter the brain. In contrast to bolus intracerebroventricular injections, continuous intracerebroventricular infusions may allow for greater drug dispersion throughout the brain parenchyma, less spillover back into the systemic circulation, and therefore less systemic toxicity. ${ }^{89}$ On the other hand, any intracerebroventricular technique is invasive, and carries both a risk of infection and a tendency to increase intracranial pressure through fluid injection. ${ }^{90,91}$

Several studies have administered AEDs by the intracerebroventricular route, with varying degrees of success. Using the rat kindling epilepsy model, VPA was delivered by either a continuous 7-day intracerebroventricular infusion, an intracerebroventricular injection, or an intraperitoneal injection. ${ }^{89}$ In general, the intracerebroventricular injection produced the highest concentrations of VPA in the CSF and ipsilateral portion of the brain, whereas the intraperitoneal injection and intracerebroventricular infusion resulted in lower, more homogeneous concentrations in the CSF and brain. Some of the VPA did exit the CSF after the intracerebroventricular injection and infusion to appear in the plasma and liver, but these amounts were much lower than after intraperitoneal injection. Administering low amounts of VPA continuously over 7 days served to reduce the incidence of toxic effects in the case of intracerebroventricular infusion, as opposed to the injection routes, which were associated with increased ataxia and sedation. All three administration techniques were able to control generalized and focal seizures, but continuous intracerebroventricular infusion of VPA is the most attractive because it achieved significant anticonvulsant effects with minimal toxicity.
A similar test of intracerebroventricular delivery was conducted with delivery of gabapentin or saline continuously to the ventricles for 5 days using a bilateral osmotic pump; the effectiveness of this approach was assessed by its ability to suppress flurothyl-induced seizures in rats. ${ }^{92}$ Methylene blue dye was added to the saline solution to visualize the approximate fluid volume of distribution. On the fifth day of infusion, the dye had spread to both hemispheres of the brain, but was localized mainly in the periventricular white matter and the ipsilateral cortex. Gabapentin concentrations in the blood were less than $1 \mu \mathrm{g} / \mathrm{mL} .^{92}$ Treatment with intracerebroventricular infusion of gabapentin increased the time for generalized tonic-clonic seizures to appear as a result of flurothyl addition, compared with control rats (338.0 \pm $89.9 \mathrm{~s}$ vs $295.8 \pm 58.8 \mathrm{~s}$ ).

\section{Intracerebral administration}

An alternative to delivering AEDs into the ventricles is to deliver them directly to the brain parenchyma through an implant or injection. Adenosine was injected into the seizure focus or the ventricles to investigate the antiepileptic effects of these delivery strategies, after seizure onset from an intracerebral injection of penicillin..$^{93}$ The intracerebroventricular injection of $100 \mu \mathrm{g}$ adenosine reduced the mean spike frequency, but not amplitude, approximately 20 min after administration. In contrast, local injection of the same amount of adenosine resulted in a decline in both the mean spike frequency and amplitude to a greater degree after $20 \mathrm{~min}$, with increasing antiepileptic effects up until $45 \mathrm{~min}$ after administration. These results suggest that local injection of adenosine is more desirable than intracerebroventricular injected adenosine, because of its enhanced anticonvulsant effects.

The main advantages of intracranial administration are bypass of the BBB, decreased systemic toxicity, and direct targeting of the seizure focus. ${ }^{93}$ As already mentioned, drugs maneuver through the brain parenchyma via diffusion, which is limited by the charge and size of the molecule, and also by the tortuosity and hindrance of the brain interstitial space. The resulting sluggish diffusion, combined with elimination mechanisms such as degradation and metabolism, causes concentrations of drug to drop with distance from the implant or injection site. ${ }^{94}$ For a polyanhydride implant containing carmustine, significant concentrations of drug were limited to only $3 \mathrm{~mm}$ away from the disk, ${ }^{95}$ whereas concentrations associated with the injection of free carmustine decreased to negligible amounts within just $1 \mathrm{~mm}$ from the administration site. ${ }^{96}$ Intracranial implants and injections also differ with respect to the time course of the drug concentrations; implants can achieve a longer time period of drug exposure due to the sustained release from a matrix, as opposed to injection, which delivers a finite 
amount of drug all at once. Using NPs that provide controlled release, the time course for drugs delivered via injections can be increased.

Polymers have been the most popular type of material used in constructing drug-releasing implants. Typically, biodegradable polymers including polyanhydrides, such as poly[bis(p-carboxyphenoxy)propane]-sebacic acid, and polyesters, such as polylactic acid, polyglycolic acid, and PLGA, have been used as intracranial implants for delivering chemotherapeutic drugs. ${ }^{97}$ In addition, anticancer drugs have been delivered through intracranial implants made of nondegradable polymers, the most popular being poly(ethylene-co-vinyl acetate) ${ }^{97}$; however, the use of nondegradable implants creates a permanent foreign object that may elicit a response and can be removed only with another surgery.

Implants have been used for delivery of AEDs. Polymeric matrices with and without gamma-aminobutyric acid (GABA) were implanted near the substantia nigra in both hemispheres of the rat brain to observe effects in the amygdala kindled epilepsy model. ${ }^{98}$ In response to electrical stimulation, rats with GABA-releasing matrices experienced lower seizure grades (i.e., less rigorous seizures) compared with control rats on the second day after introduction of the implant; however, the GABA levels dropped so low on the 7th day after implantation that the antiepileptic effects of the drug-loaded matrices were greatly reduced.

Polymeric matrices loaded with thyrotropin-releasing hormone (TRH) have been implanted into the amygdala of kindled rats. ${ }^{99}$ (TRH is not a traditional AED, but has had some success in animal models of epilepsy through eliciting temporary anticonvulsive effects.) In the rats receiving TRH from the implant, the progress of the kindling procedure was hindered; specifically, the amount of electrical stimulations and time necessary to advance through each kindling stage was increased in rats given TRH-releasing disks. Some antiepileptic effects persisted even at 50 days after implantation.

In another study, phenytoin was encapsulated into a nonbiodegradable, controlled-release polymer that was implanted 1-2 mm deep into the cortex in rats. ${ }^{100}$ The rats receiving phenytoin from the implant showed a significant decrease in the prevalence of spikes appearing in the electrocorticographs, compared with the control group, when seizures were induced by the addition of cobalt chloride to the cortex. Although not directly shown, the phenytoin implant was designed to release the drug for up to 3.5 years. This duration of release is technically achievable for implants with a number of agents: for example, the Norplant system (Leiras Oy, Turku, Finland) releases contraceptive steroids for over 5 years and small protein-loaded implants can release protein for over 2 years. ${ }^{101}$

Recently, bioceramic materials have been investigated as implantable, sustained release delivery vehicles for AEDs.
A sol-gel titania $\left(\mathrm{TiO}_{2}\right)$ reservoir containing VPA was implanted into the basolateral amygdala in kindled rats. ${ }^{102}$ Upon histological examination after 12 months, the titania devices appeared intact and showed no evidence of neuronal injury. Reservoirs containing the lowest dose of VPA, $200 \mathrm{mg}$ per $20 \mathrm{~g}$ of titania, shielded rats from pentylenetetrazol-induced seizures compared with controls for up to 5 months after implantation. A titania reservoir containing phenytoin has also been tested, with similar histological results ${ }^{103}$; the device exhibited biocompatibility and did not cause any damage to proximate neurons when placed in the temporal lobe of Wistar rats. However, the anticonvulsive activity of phenytoin was not assessed.

Direct intracerebral delivery may allow use of new classes of drugs. Within the last few years, several groups have injected a variety of AEDs intracerebrally, and observed their effects in animal models of epilepsy. Progesterone, a GABA agonist, and tiagabine, a selective inhibitor that prevents reuptake of GABA, were injected bilaterally into the hippocampus and tested for their ability to prevent absence seizures in the WAG/Rij (Wistar Albino Glaxo from Rijswijk) rat model of epilepsy. ${ }^{104}$ Up to 60 min after direct injection into the hippocampus, both progesterone and tiagabine proved effective in decreasing the incidence of spike-wave discharges in the absence seizure rats without inducing any adverse effects.

The amygdala kindled rat model of epilepsy was used to test the direct injection of lidocaine, which briefly suppresses neuronal activity, into both sides of the rat hippocampus. ${ }^{105}$ The local injection of lidocaine into the hippocampus produced anticonvulsive effects by reducing the severity of seizures and slowing the speed at which the kindling process progressed. In another study, adenosine was injected into the left hippocampus of rats and studied for its effects on seizures induced by bicuculline methiodide. ${ }^{106}$ Focal injection of adenosine elicited some control of seizures that was observed as a decrease in the occurrence of epileptiform electrical activity, specifically total spikes and ictal events, on the electroencephalogram. There have been instances, however, in which intracerebral administration has not been proven to be effective. For example, when muscimol, a GABA receptor agonist, was delivered intracraniallyand phenobarbital was delivered both intracranially and systemically - only the intraperitoneal injection of 15 $\mathrm{mg} / \mathrm{kg}$ of phenobarbital produced nearly complete elimination of sound-induced seizures in audiogenic Wistar rats, and did not cause any adverse effects. ${ }^{107}$

\section{Convection-enhanced delivery}

Convection-enhanced delivery (CED) was developed as an alternative to intraparenchymal injections to enhance drug distribution throughout the brain. ${ }^{108}$ In CED, a drug solution is gradually infused into a catheter placed locally in the brain interstitial space, which causes con- 
vective as well as diffusive movement of drug due to an externally applied pressure source. The typical CED apparatus is made of a small catheter connected to a pump. ${ }^{109}$ Pressure created by the pump causes fluid to flow out of the catheter and into the brain interstitium. As a result of flow, which carries molecules into the brain more rapidly than diffusion, the distribution volume of drug in the brain is enlarged, compared with the volume under intraparenchymal injection and implantation. Experimental work to date suggests some general principles for CED operation. Smaller molecules tend to travel a greater distance than larger molecules or particles. ${ }^{110}$ Molecules with a neutral or negative charge, or liposomes coated with either PEG or bovine serum albumin, exhibit a larger distribution volume in the brain than positively charged agents of the same size. ${ }^{20}$

Convection-enhanced delivery provides a way to treat a seizure focus locally, avoiding the BBB and reducing systemic toxicity. Despite these advantages, CED has drawbacks. The high pressures associated with convective flow can cause fluid to flow back along the outside of the catheter, typically either into the subarachnoid space or into white matter tracts, which have a lower resistance to flow than do gray matter regions. ${ }^{111}$ These inadvertent flows cause inefficient drug delivery. In addition, poor placement of the catheter within the brain can lead to tissue injury and the presence of air bubbles. ${ }^{12}$ With traditional catheters, which have outlets at the leading edge, introduction into the brain can create a tissue plug within the catheter outlet, which blocks fluid flow. Recently, microfluidic devices have been developed with a fluid outlet on the side of the device that is perpendicular to the direction of insertion, which decreases the extent of tissue damage and backflow. ${ }^{113}$

In the past few years, some groups have explored CED methods as a possible treatment for epilepsy. Muscimol was delivered into the hippocampus of rhesus monkeys to test the safety and efficacy of CED. ${ }^{114}$ Muscimol was distributed throughout the ipsilateral hippocampus and medial temporal lobe, whereas little muscimol was found in venous blood. Neurological function appeared normal after the monkeys received either the vehicle alone or the lowest amount of muscimol, $0.125 \mathrm{mmol} / \mathrm{L}$; however, increasing the muscimol concentration to $0.5 \mathrm{mmol} / \mathrm{L}$ and $1 \mathrm{mmol} / \mathrm{L}$ caused transient sedation. Histological results showed a small amount of gliosis directly surrounding the catheter, but no other problems. Although this study suggests that CED to the hippocampus is safe, further work is needed to determine the antiepileptic efficacy of muscimol delivered by CED.

In another study, $\omega$-conotoxin GVIA (isolated from Conus geographus cone snail) and $\omega$-conotoxin MVIIA (isolated from C. magus) were delivered with CED to the basolateral amygdala of kindled rats. ${ }^{108}$ Both peptides are antagonists of $\mathrm{N}$-type calcium channels, which have been found to elicit anticonvulsant effects in brain slices. Twenty-minute infusions of either drug resulted in antiepileptic activity that lasted for approximately 1 week and peaked at 2 days after infusion. The only toxic effects occurring from the use of these drugs were tremors associated with the maximum doses $(0.5 \mathrm{nmol}$ per infusion). This study shows that CED can be both safe and effective for treating seizures.

\section{CONCLUSION}

The BBB is the major factor limiting the efficacy of the typical AED treatments, which has inspired the creation of new strategies to increase the penetration and persistence of AEDs in the brain parenchyma. First, drugs have been encapsulated into delivery systems enhanced with stealth polymers for increased circulation and ligands for targeting specific locations. Second, prodrugs have been developed through the addition of cleavable moieties that render the free drug inactive until the target destination has been reached. Third, alteration of the BBB has been achieved through the inhibition of efflux pumps or through the addition of hyperosmolar substances to increase the permeability through brain capillary endothelial cells. (Disruption of the BBB is not recommended for use in epileptic patients, however, because the procedure itself results in seizures.) Fourth, direct delivery of drugs to the ventricles or brain parenchyma has the potential to increase the delivery of AEDs to the brain by bypassing the BBB altogether.

Each of the four approaches has advantages and disadvantages. Some drug delivery systems are capable of sustained release, which reduce the frequency of administration. Drug delivery systems and prodrugs are both capable of penetrating the BBB, although no drug delivery systems have yet been translated to clinical useperhaps because of difficulty in achieving the penetration of a sufficient fraction of the particulate dose to yield efficacy without adverse effects in other tissues. Alterations of the BBB, particularly osmotic opening of the barrier, are risky. For example, inhibition of efflux pumps as a treatment for epilepsy remains controversial. Although there has been some initial success with this technique, it is not yet clear whether most AEDs are valid substrates for Pgp, MRPs, and BCRP, and more specific inhibitors need to be developed.

Drug delivery systems, prodrugs, and alterations of the $\mathrm{BBB}$ all share the disadvantage that they require the transport of drugs across the $\mathrm{BBB}$; it remains difficult to design truly specific BBB transport enhancers that do not also act on vessels in other tissues. Direct delivery circumvents the need for BBB crossing by administering drugs directly into the ventricles or cortex. Of the direct drug delivery strategies, intracerebroventricular administration is the least efficient due to limited drug pene- 
tration from the CSF to the brain (with more localization at the ependymal surface) and spillover back into the systemic circulation. Both intracerebral administration and CED are more desirable, because direct targeting of the seizure focus and greater concentrations of drug in the brain parenchyma can be achieved. Convection-enhanced delivery has an additional advantage over intracerebral administration in that convective flow increases the volume of drug distribution in the brain. On the other hand, the high pressures required for CED can cause backflow along the catheter, resulting in inefficient drug delivery, and may cause mechanical damage to tissue.

These novel alternatives to traditional oral and intravenous delivery methods will undoubtedly lead to more effective treatments for patients with epilepsy in the future. Prodrugs have already had a substantial influence on clinical treatments of brain disease. Drug delivery systems are already available for treating some diseases, such as cancer, and progress in this area for epilepsy is possible over the next 5 years. Direct delivery methods are already used routinely for brain tumor therapy and could be developed for epilepsy within the next 5 years. It is more difficult to predict the future of methods for BBB alteration.

With the constellation of technologies available, a coordinated effort among basic scientists, bioengineers, and clinicians could bring safer and more effective treatments to epilepsy patients.

Acknowledgments: The authors thank Dr. Christopher Hoimes for helpful background discussions and Audrey Lin for expert editorial assistance and preparation of illustrations.

\section{REFERENCES}

1. De Tiège $X$, Laufs H, Boyd SG, et al. EEG-fMRI in children with pharmacoresistant focal epilepsy. Epilepsia 2007;48:385-389.

2. Pardridge WM. Blood-brain barrier drug targeting: the future of brain drug development. Mol Interv 2003;3:90-105, 51.

3. Barnett GH. High-grade gliomas: diagnosis and treatment. Totowa, NJ: Humana Press, 2006.

4. Abbott NJ, Rönnbäck L, Hansson E. Astrocyte-endothelial interactions at the blood-brain barrier. Nat Rev Neurosci 2006;7:41-53.

5. Fisher RS, Ho J. Potential new methods for antiepileptic drug delivery. CNS Drugs 2002;16:579-593.

6. Müller RH. Colloidal carriers for controlled drug delivery and targeting: modification, characterization, and in vivo distribution. Boca Raton, FL: CRC Press, 1991.

7. Yang SC, Lu LF, Cai Y, Zhu JB, Liang BW, Yang CZ. Body distribution in mice of intravenously injected camptothecin solid lipid nanoparticles and targeting effect on brain. J Control Release 1999;59:299-307.

8. Muller RH, Petersen RD, Hommoss A, Pardeike J. Nanostructured lipid carriers (NLC) in cosmetic dermal products. Adv Drug Deliv Rev 2007;59:522-530.

9. Saad M, Garbuzenko OB, Ber E, et al. Receptor targeted polymers, dendrimers, liposomes: which nanocarrier is the most efficient for tumor-specific treatment and imaging? J Control Release 2008;130:107-114.

10. Klingeler R, Hampel S, Büchner B. Carbon nanotube based biomedical agents for heating, temperature sensing and drug delivery. Int J Hyperthermia 2008;24:496-505.

11. Couvreur P, Vauthier C. Nanotechnology: intelligent design to treat complex disease. Pharm Res 2006;23:1417-1450.
12. Barratt GM. Therapeutic applications of colloidal drug carriers. Pharm Sci Technolo Today 2000;3:163-171.

13. Sharma A, Sharma US. Liposomes in drug delivery: progress and limitations. Int J Pharm 1997;154:123-140.

14. Dutt M, Khuller GK. Liposomes and PLG microparticles as sustained release antitubercular drug carriers: an in vitro-in vivo study. Int J Antimicrob Agents 2001;18:245-252.

15. Verdun C, Brasseur F, Vranckx H, Couvreur P, Roland M. Tissue distribution of doxorubicin associated with polyisohexylcyanoacrylate nanoparticles. Cancer Chemother Pharmacol 1990;26: $13-18$.

16. Date AA, Joshi MD, Patravale VB. Parasitic diseases: liposomes and polymeric nanoparticles versus lipid nanoparticles. Adv Drug Deliv Rev 2007;59:505-521.

17. Thorne RG, Nicholson C. In vivo diffusion analysis with quantum dots and dextrans predicts the width of brain extracellular space. Proc Natl Acad Sci U S A 2006;103:5567-5572.

18. Birnbaum DT, Kosmala JD, Brannon-Peppas L. Optimization of preparation techniques for poly(lactic acid-co-glycolic acid) nanoparticles. J Nanoparticle Res 2000;2:173-181.

19. Ito F, Fujimori H, Makino K. Incorporation of water-soluble drugs in PLGA microspheres. Colloids Surf B Biointerfaces 2007;54:173-178.

20. MacKay J, Deen DF, Szoka FC Jr. Distribution in brain of liposomes after convection enhanced delivery: modulation by particle charge, particle diameter, and presence of steric coating. Brain Res 2005;1035:139-153.

21. Jain RA. The manufacturing techniques of various drug loaded biodegradable poly(lactide-co-glycolide) (PLGA) devices. Biomaterials 2000;21:2475-2490.

22. Lockman PR, Mumper RJ, Khan MA, Allen DD. Nanoparticle technology for drug delivery across the blood-brain barrier. Drug Dev Ind Pharm 2002;28:1-13.

23. Yasukawa T, Ogura Y, Sakurai E, Tabata Y, Kimura H. Intraocular sustained drug delivery using implantable polymeric devices. Adv Drug Deliv Rev 2005;57:2033-2046.

24. Paasonen L, Romberg B, Storm G, Yliperttula M, Urtti A, Hennink WE. Temperature-sensitive poly( $N$-(2-hydroxypropyl) methacrylamide mono/dilactate)-coated liposomes for triggered contents release. Bioconjug Chem 2007;18:2131-2136.

25. Drummond DC, Zignani M, Leroux J. Current status of $\mathrm{pH}-$ sensitive liposomes in drug delivery. Prog Lipid Res 2000;39: 409-460.

26. Alexis F, Pridgen E, Molnar LK, Farokhzad OC. Factors affecting the clearance and biodistribution of polymeric nanoparticles. Mol Pharm 2008;5:505-515.

27. Van Vlerken LE, Vyas TK, Amiji MM. Poly(ethylene glycol)modified nanocarriers for tumor-targeted and intracellular delivery. Pharm Res 2007;24:1405-1414.

28. Peracchia MT, Fattal E, Desmaële D, et al. Stealth PEGylated polycyanoacrylate nanoparticles for intravenous administration and splenic targeting. J Control Release 1999;60:121-128.

29. Panagi Z, Beletsi A, Evangelatos G, Livaniou E, Ithakissios DS, Avgoustakis K. Effect of dose on the biodistribution and pharmacokinetics of PLGA and PLGA-mPEG nanoparticles. Int J Pharm 2001;221:143-152.

30. Gabizon A, Shmeeda H, Barenholz Y. Pharmacokinetics of pegylated liposomal doxorubicin: review of animal and human studies. Clin Pharmacokinet 2003;42:419-436.

31. Lee C-M, Choi Y, Huh EJ, et al. Polyethylene glycol (PEG) modified ${ }^{99 \mathrm{~m}} \mathrm{Tc}-\mathrm{HMPAO}-$ liposome for improving blood circulation and biodistribution: the effect of the extent of PEGylation. Cancer Biother Radiopharm 2005;20:620-628.

32. Jeon SI, Lee JH, Andrade JD, De Gennes PG. Protein-surface interactions in the presence of polyethylene oxide: I. Simplified theory. J Colloid Interface Sci 1991;142:149-158.

33. Owens DE 3rd, Peppas NA. Opsonization, biodistribution, and pharmacokinetics of polymeric nanoparticles. Int J Pharm 2006; 307:93-102.

34. Rapoport S. Modulation of blood-brain barrier permeability. J Drug Target 1996;3:417-425.

35. Béduneau A, Saulnier P, Benoit JP. Active targeting of brain tumors using nanocarriers. Biomaterials 2007;28:4947-4967. 
36. Schnyder A, Huwyler J. Drug transport to brain with targeted liposomes. NeuroRx 2005;2:99-107.

37. Umezawa F, Eto Y. Liposome targeting to mouse brain: mannose as a recognition marker. Biochem Biophys Res Commun 1988; 153:1038-1044.

38. Mora M, Sagristá ML, Trombetta D, Bonina FP, De Pasquale A, Saija A. Design and characterization of liposomes containing long-chain N-acylPEs for brain delivery: penetration of liposomes incorporating GM1 into the rat brain. Pharm Res 2002;19: $1430-1438$

39. Fenart L, Casanova A, Dehouck B, et al. Evaluation of effect of charge and lipid coating on ability of 60-nm nanoparticles to cross and in vitro model of the blood-brain barrier. J Pharmacol Exp Ther 1999;291:1017-1022.

40. Allen DD, Lockman PR. The blood-brain barrier choline transporter as a brain drug delivery vector. Life Sci 2003;73:16091615.

41. Friese A, Seiller E, Quack G, Lorenz B, Kreuter J. Increase of the duration of the anticonvulsive activity of a novel NMDA receptor antagonist using poly(butylcyanoacrylate) nanoparticles as a parenteral controlled release system. Eur J Pharm Biopharm 2000; 49:103-109.

42. Kreuter J, Shamenkov D, Petrov V, et al. Apolipoprotein-mediated transport of nanoparticle-bound drugs across the bloodbrain barrier. J Drug Target 2002;10:317-325.

43. Olivier JC. Drug transport to brain with targeted nanoparticles. NeuroRx 2005;2:108-119.

44. Aktaş Y, Yemisci M, Andrieux K, et al. Development and brain delivery of chitosan-PEG nanoparticles functionalized with the monoclonal antibody OX26. Bioconjug Chem 2005;16:15031511.

45. Huwyler J, Wu D, Pardridge WM. Brain drug delivery of small molecules using immunoliposomes. Proc Natl Acad Sci U S A 1996;93:14164-14169.

46. Schnyder A, Krähenbühl S, Drewe J, Huwyler J. Targeting of daunomycin using biotinylated immunoliposomes: pharmacokinetics, tissue distribution and in vitro pharmacological effects. J Drug Target 2005;13:325-335.

47. Huwyler J, Yang J, Pardridge WM. Receptor mediated delivery of daunomycin using immunoliposomes: pharmacokinetics and tissue distribution in the rat. J Pharmacol Exp Ther 1997;282: 1541-1546.

48. Cerletti A, Drewe J, Fricker G, Eberle AN, Huwyler J. Endocytosis and transcytosis of an immunoliposome-based brain drug delivery system. J Drug Target 2000;8:435-446.

49. Kelly K. Gabapentin: antiepileptic mechanism of action. Neuropsychobiology 1998;38:139-144.

50. Trojnar MK, Wierzchowska-Cioch E, Krzyzanowski M, Jargiełło $\mathrm{M}$, Czuczwar SJ. New generation of valproic acid. Pol J Pharmacol 2004;56:283-288.

51. Bialer M, Johannessen SI, Kupferberg HJ, Levy RH, Loiseau P, Perucca E. Progress report on new antiepileptic drugs: a summary of the fifth Eilat conference (EILAT V). Epilepsy Res 2001;43: $11-58$.

52. Rautio J, Kumpulainen H, Heimbach T, et al. Prodrugs: design and clinical applications [Erratum in: Nat Rev Drug Discov 2008; 7:272]. Nat Rev Drug Discov 2008;7:255-270.

53. Fechner J, Schwilden H, Schüttler J. Pharmacokinetics and pharmacodynamics of GPI 15715 or fospropofol (Aquavan injection): a water-soluble propofol prodrug. Handb Exp Pharmacol 2008; 182:253-266.

54. Knapp LE, Kugler AR. Clinical experience with fosphenytoin in adults: pharmacokinetics, safety, and efficacy. J Child Neurol 1998;13 Suppl 1:S15-S18; discussion S30-S32.

55. Cundy KC, Branch R, Chernov-Rogan T, et al. XP13512 [( \pm 1-([( $\alpha$-Isobutanoyloxyethoxy)carbonyl]aminomethyl)-1-cyclohexane acetic acid], a novel gabapentin prodrug: I. design, synthesis, enzymatic conversion to gabapentin, and transport by intestinal solute transporters. J Pharmacol Exp Ther 2004;311:315-323.

56. Cundy KC, Annamalai T, Bu L, et al. XP13512 [( \pm$)-1-([(\alpha-$ Isobutanoyloxyethoxy)carbonyl]aminomethyl)-1-cyclohexane acetic acid], a novel gabapentin prodrug: II. Improved oral bioavailability, dose proportionality, and colonic absorption compared with gabapentin in rats and monkeys. J Pharmacol Exp Ther 2004;311:324-333.

57. Löscher W, Potschka H. Blood-brain barrier active efflux transporters: ATP-binding cassette gene family. NeuroRx 2005;2: 86-98.

58. Tishler DM, Weinberg KI, Hinton DR, Barbaro N, Annett GM, Raffel C. MDR1 gene expression in brain of patients with medically intractable epilepsy. Epilepsia 1995;36:1-6.

59. Potschka H, Fedrowitz M, Löscher W. Multidrug resistance protein MRP2 contributes to blood-brain barrier function and restricts antiepileptic drug activity. J Pharmacol Exp Ther 2003; 306:124-131.

60. Aronica E, Gorter JA, Jansen GH, et al. Expression and cellular distribution of multidrug transporter proteins in two major causes of medically intractable epilepsy: focal cortical dysplasia and glioneuronal tumors. Neuroscience 2003;118:417-429.

61. Sisodiya SM, Lin WR, Squier MV, Thom M. Multidrug-resistance protein 1 in focal cortical dysplasia. Lancet 2001;357: 42-43.

62. Dombrowski SM, Desai SY, Marroni M, et al. Overexpression of multiple drug resistance genes in endothelial cells from patients with refractory epilepsy. Epilepsia 2001;42:1501-1506.

63. Lazarowski A, Ramos AJ, García-Rivello H, Brusco A, Girardi E. Neuronal and glial expression of the multidrug resistance gene product in an experimental epilepsy model. Cell Mol Neurobiol 2004;24:77-85.

64. Chengyun D, Guoming L, Elia M, Catania M, Qunyuan X. Expression of multidrug resistance type 1 gene (MDR1) P-glycoprotein in intractable epilepsy with different aetiologies: a doublelabelling and electron microscopy study. Neurol Sci 2006;27: 245-251.

65. Aronica E, Gorter JA, Ramkema M, et al. Expression and cellular distribution of multidrug resistance-related proteins in the hippocampus of patients with mesial temporal lobe epilepsy. Epilepsia 2004;45:441-451.

66. Sisodiya SM, Martinian L, Scheffer GL, et al. Vascular colocalization of P-glycoprotein, multidrug-resistance associated protein 1 , breast cancer resistance protein, and major vault protein in human epileptogenic pathologies. Neuropathol Appl Neurobiol 2006;32:51-63.

67. Vogelgesang S, Kunert-Keil C, Cascorbi I, et al. Expression of multidrug transporters in dysembryoplastic neuroepithelial tumors causing intractable epilepsy. Clin Neuropathol 2004;23: 223-231.

68. Summers MA, Moore JL, McAuley JW. Use of verapamil as a potential P-glycoprotein inhibitor in a patient with refractory epilepsy. Ann Pharmacother 2004;38:1631-1634.

69. Iannetti P, Spalice A, Parisi P. Calcium-channel blocker verapamil administration in prolonged and refractory status epilepticus. Epilepsia 2005;46:967-969.

70. Brandt C, Bethmann K, Gastens AM, Löscher W. The multidrug transporter hypothesis of drug resistance in epilepsy: proof-ofprinciple in a rat model of temporal lobe epilepsy. Neurobiol Dis 2006;24:202-211.

71. Thomas H, Coley HM. Overcoming multidrug resistance in cancer: an update on the clinical strategy of inhibiting P-glycoprotein. Cancer Control 2003;10:159-165.

72. Van Vliet EA, Redeker S, Aronica E, Edelbroek PM, Gorter JA Expression of multidrug transporters MRP1, MRP2, and BCRP shortly after status epilepticus, during the latent period, and in chronic epileptic rats. Epilepsia 2005;46:1569-1580.

73. Baltes S, Gastens AM, Fedrowitz M, Potschka H, Kaever V, Löscher W. Differences in the transport of the antiepileptic drugs phenytoin, levetiracetam and carbamazepine by human and mouse P-glycoprotein. Neuropharmacology 2007;52:333-346.

74. Cerveny L, Pavek P, Malakova J, Staud F, Fendrich Z. Lack of interactions between breast cancer resistance protein (BCRP/ ABCG2) and selected antiepileptic agents. Epilepsia 2006;47: 461-468.

75. Haluska M, Anthony ML. Osmotic blood-brain barrier modification for the treatment of malignant brain tumors. Clin $\mathrm{J}$ Oncol Nurs 2004;8:263-267.

76. Siegal T, Rubinstein R, Bokstein F, et al. In vivo assessment of 
the window of barrier opening after osmotic blood-brain barrier disruption in humans. J Neurosurg 2000;92:599-605.

77. Kraemer DF, Fortin D, Doolittle ND, Neuwelt EA. Association of total dose intensity of chemotherapy in primary central nervous system lymphoma (human non-acquired immunodeficiency syndrome) and survival. Neurosurgery 2001;48:1033-1040; discussion 1040-1041.

78. Kroll RA, Neuwelt EA. Outwitting the blood-brain barrier for therapeutic purposes: osmotic opening and other means. Neurosurgery 1998;42:1083-1099.

79. Marchi N, Angelov L, Masaryk T, et al. Seizure-promoting effect of blood-brain barrier disruption. Epilepsia 2007;48:732-742.

80. van Vliet EA, da Costa Araújo S, Redeker S, van Schaik R, Aronica E, Gorter JA. Blood-brain barrier leakage may lead to progression of temporal lobe epilepsy. Brain 2007;130:521-534.

81. Bakhshi S, North RB. Implantable pumps for drug delivery to the brain. J Neurooncol 1995;26:133-139.

82. Pardridge WM. Drug delivery to the brain. J Cereb Blood Flow Metab 1997;17:713-731.

83. Brightman MM, Kaya M. Permeable endothelium and the interstitial space of brain. Cell Mol Neurobiol 2000;20:111-130.

84. Tao A, Tao L, Nicholson C. Cell cavities increase tortuosity in brain extracellular space. J Theor Biol 2005;234:525-536.

85. Pardridge WM. Transport of small molecules through the bloodbrain barrier: biology and methodology. Adv Drug Deliv Rev 1995;15:5-36.

86. Aird RB. A study of intrathecal, cerebrospinal fluid-to-brain exchange. Exp Neurol 1984;86:342-358.

87. Billiau A, Heremans H, Ververken D, Van Damme J, Carton H, De Somer P. Tissue distribution of human interferons after exogenous administration in rabbits, monkeys, and mice. Arch Virol 1981;68:19-25.

88. Covell DG, Narang PK, Poplack DG. Kinetic model for disposition of 6-mercaptopurine in monkey plasma and cerebrospinal fluid. Am J Physiol Regul Integr Comp Physiol 1985;17:R147R156.

89. Serralta A, Barcia JA, Ortiz P, Durán C, Hernández ME, Alós M. Effect of intracerebroventricular continuous infusion of valproic acid versus single i.p. and i.c.v. injections in the amygdala kindling epilepsy model. Epilepsy Res 2006;70:15-26.

90. Boogerd W, van den Bent MJ, Koehler PJ, et al. The relevance of intraventricular chemotherapy for leptomeningeal metastasis in breast cancer: a randomised study. Eur J Cancer 2004;40:27262733.

91. Sandberg DI, Bilsky MH, Souweidane MM, Bzdil J, Gutin PH. Ommaya reservoirs for the treatment of leptomeningeal metastases. Neurosurgery 2000;47:49-54.

92. Oommen J, Kraus A, Fisher R. Intraventricular administration of gabapentin in the rat increases flurothyl seizure threshold. Neurosci Lett 2007;417:308-311.

93. Yildirim M, Marangoz C. Anticonvulsant effects of focal and intracerebroventricular adenosine on penicillin-induced epileptiform activity in rats. Brain Res 2007;1127:193-200.

94. Saltzman WM, Olbricht WL. Building drug delivery into tissue engineering. Nat Rev Drug Discov 2002;1:177-187.

95. Fung LK, Ewend MG, Sills A, et al. Pharmacokinetics of interstitial delivery of carmustine, 4-hydroperoxycyclophosphamide, and paclitaxel from a biodegradable polymer implant in the monkey brain. Cancer Res 1998;58:672-684.

96. Fung LK, Shin M, Tyler B, Brem H, Saltzman WM. Chemotherapeutic drugs released from polymers: distribution of 1,3-bis(2chloroethyl)-1-nitrosourea in the rat brain. Pharm Res 1996;13: 671-682.

97. Sawyer AJ, Piepmeier JM, Saltzman WM. New methods for direct delivery of chemotherapy for treating brain tumors. Yale J Biol Med 2006;79:141-152.

98. Kokaia M, Aebischer P, Elmér E, et al. Seizure suppression in kindling epilepsy by intracerebral implants of GABA-but not by noradrenaline-releasing polymer matrices. Exp Brain Res 1994; 100:385-394.

99. Kubek MJ, Liang D, Byrd KE, Domb AJ. Prolonged seizure suppression by a single implantable polymeric-TRH microdisk preparation. Brain Res 1998;809:189-197.
100. Tamargo RJ, Rossell LA, Kossoff EH, Tyler BM, Ewend MG, Aryanpur JJ. The intracerebral administration of phenytoin using controlled-release polymers reduces experimental seizures in rats. Epilepsy Res 2002;48:145-155.

101. Saltzman WM, Langer R. Transport rates of proteins in porous materials with known microgeometry. Biophys J 1989;55:163171.

102. Lopez T, Ortiz E, Quintana P, Gonzalez RD. A nanostructured titania bioceramic implantable device capable of drug delivery to the temporal lobe of the brain. Colloids Surf A Physicochem Eng Asp 2007;300:3-10.

103. Lopez T, Quintana P, Ascencio J, Gonzalez RD. The determination of dielectric constants of mixtures used in the treatment of epilepsy and the encapsulation of phenytoin in a titania matrix. Colloids Surf A Physicochem Eng Asp 2007;300:99-105.

104. Tolmacheva EA, Van Luijtelaar G. Absence seizures are reduced by the enhancement of GABA-ergic inhibition in the hippocampus in WAG/Rij rats. Neurosci Lett 2007;416:17-21.

105. Mirnajafi-Zadeh J, Mortazavi M, Fathollahi Y, Alasvand Zarasvand M, Reza Palizvan M. Effect of transient hippocampal inhibition on amygdaloid kindled seizures and amygdaloid kindling rate. Brain Res 2002;954:220-226.

106. Anschel DJ, Ortega EL, Kraus AC, Fisher RS. Focally injected adenosine prevents seizures in the rat. Exp Neurol 2004;190:544547.

107. Rossetti F, Rodrigues MCA, de Oliveira JAC, Garcia-Cairasco N. EEG wavelet analyses of the striatum-substantia nigra pars reticulata-superior colliculus circuitry: audiogenic seizures and anticonvulsant drug administration in Wistar audiogenic rats (War strain). Epilepsy Res 2006;72:192-208.

108. Gasior M, White NA, Rogawski MA. Prolonged attenuation of amygdala-kindled seizure measures in rats by convection-enhanced delivery of the N-type calcium channel antagonists $\omega$-conotoxin GVIA and $\omega$-conotoxin MVIIA. J Pharmacol Exp Ther 2007;323:458-468.

109. Morrison PF, Chen MY, Chadwick RS, Lonser RR, Oldfield EH. Focal delivery during direct infusion to brain: role of flow rate, catheter diameter, and tissue mechanics [Erratum in: Am J Physiol Regul Integr Comp Physiol 2002;282(6):section R following table of contents]. Am J Physiol Regul Integr Comp Physiol 1999;277:R1218-R1229.

110. Chen MY, Hoffer A, Morrison PF, et al. Surface properties, more than size, limiting convective distribution of virus-sized particles and viruses in the central nervous system. J Neurosurg 2005;103: 311-319.

111. Chen MY, Lonser RR, Morrison PF, Governale LS, Oldfield EH. Variables affecting convection-enhanced delivery to the striatum: a systemic examination of rate of infusion, cannula size, infusate concentration, and tissue-cannula sealing time. J Neurosurg 1999;90:315-320.

112. Raghavan R, Brady M, Rodriguez-Ponce M, Hartlep A, Pedain C, Sampson J. Convection-enhanced delivery of therapeutics for brain disease and its optimization. Neurosurg Focus 2006;20(4): E12.

113. Neeves KB, Lo CT, Foley CP, Saltzman WM, Olbricht WL. Fabrication and characterization of microfluidic probes for convection enhanced drug delivery. J Control Release 2006;111:252 262.

114. Heiss JD, Walbridge S, Morrison P, et al. Local distribution and toxicity of prolonged hippocampal infusion of muscimol. J Neurosurg 2005;103:1035-1045.

115. Zara GP, Cavalli R, Bargoni A, Fundarò A, Vighetto D, Gasco MR. Intravenous administration to rabbits of non-stealth and stealth doxorubicin-loaded solid lipid nanoparticles at increasing concentrations of stealth agent: pharmacokinetics and distribution of doxorubicin in brain and other tissues. J Drug Target 2002;10: 327-335.

116. Yan Q, Matheson C, Sun J, Radeke MJ, Feinstein SC, Miller JA. Distribution of intracerebral ventricularly administered neurotrophins in rat brain and its correlation with Trk receptor expression. Exp Neurol 1994;127:23-36. 